\title{
Comparing the environmental impact of anesthetic gases during transanal total mesorectal excision surgery at a tertiary healthcare centre
}

\author{
Antonio Caycedo-Marulanda, MD, MSc $\mathbb{~} \cdot$ Joseph Caswell, PhD • \\ Sanjiv Mathur, MD
}

Received: 8 October 2019/Revised: 2 November 2019/Accepted: 4 November 2019/Published online: 12 November 2019

(C) Canadian Anesthesiologists' Society 2019

\section{To the Editor,}

The World Health Organization has identified climate change as the greatest threat to global health in this century. ${ }^{1}$ The Canadian Medical Association policy paper on climate change and human health states "the global community needs to act together to address the health and environmental impacts of climate change". A Volatile anesthetic agents have been identified as strong greenhouse gases. ${ }^{2}$ Anesthetic gases constitute one of the largest contributors to the carbon footprint of the operating room. ${ }^{3}$ The sustainable development unit of the National Health Services in the UK recommended that measuring, monitoring, and reporting the carbon dioxide equivalence (CDE) is crucial for reducing emissions of medical activity. ${ }^{\mathrm{B}}$ Recently, Hanna and Bryson graphically exemplified the significant differences in CDE among various anesthetic agents. ${ }^{4} \mathrm{We}$ similarly calculated the $\mathrm{CDE}$ and kilometers driving equivalence (KmDE) of volatile anesthetics gases delivered during a novel surgical procedure (transanal total mesorectal excision [taTME]) over an 18-month period at Health Sciences North, a tertiary healthcare institution in Sudbury, Ontario.

\footnotetext{
A. Caycedo-Marulanda, MD, MSc ( $\square)$

Surgery Department, Health Sciences North, Sudbury, ON, Canada

e-mail: caycedomd@gmail.com

J. Caswell, PhD

ICES North, Sudbury, ON, Canada
}

S. Mathur, MD

Department of Anesthesia, Health Sciences North, Sudbury, ON, Canada
The electronic anesthetic records of all taTME procedures between 1 January 2017 to 30 June 2018 were analyzed for volatile concentration, fresh gas flow, and duration of anesthetic gas delivery. Institutional review board approval was obtained to conduct this retrospective study. The CDE was calculated using the Yale Gassing Greener program created by Yale Anesthesiology Media Lab. $^{\mathrm{C}}$ The KmDE was calculated using the CDE produced and the assumption of driving a gas-powered vehicle with a fuel consumption of $28 \mathrm{mpg}$. We compared the CDE and $\mathrm{KmDE}$ in taTME procedures using sevoflurane (SEVO) or desflurane (DES). Values were compared using a $t$ test. The time to reach Aldrete score of 9 (which is used to determine when patients can be safely discharged from the postanesthetic care unit [PACU]), the incidence of major perioperative morbidity events, and mortality rate were also compared.

Sixty-three procedures were performed during the study period (five patients were excluded because of incomplete records and one because $\mathrm{N}_{2} \mathrm{O}$ was used). In 38 cases, SEVO was used as the anesthetic gas and the median [interquartile range (IQR)] $\mathrm{CDE}$ was 8.4 [7.4] $\mathrm{kg}$ of $\mathrm{CO}_{2}$ and the KmDE was 33.1 [29.0] km. Desflurane (DES) was the agent of choice for 19 cases. The median [IQR] CDE produced was 408.6 [154.4] $\mathrm{kg}$ of $\mathrm{CO}_{2}$ and the $\mathrm{KmDE}$ was $1,602[605] \mathrm{km}$. The CDE and $\mathrm{KmDE}$ were dramatically lower in the SEVO group $(P<0.001)$ (Figure). The ASA physical status, age, and duration of anesthesia did not differ between the groups. There was no significant difference in the time between the two groups to be discharged from the PACU as determined by Aldrete's

\footnotetext{
A https://policybase.cma.ca/.

B www.sduhealth.org.uk.

${ }^{\mathrm{C}}$ https://apps.apple.com/us/app/yale-gassing-greener/id1152700062.
} 

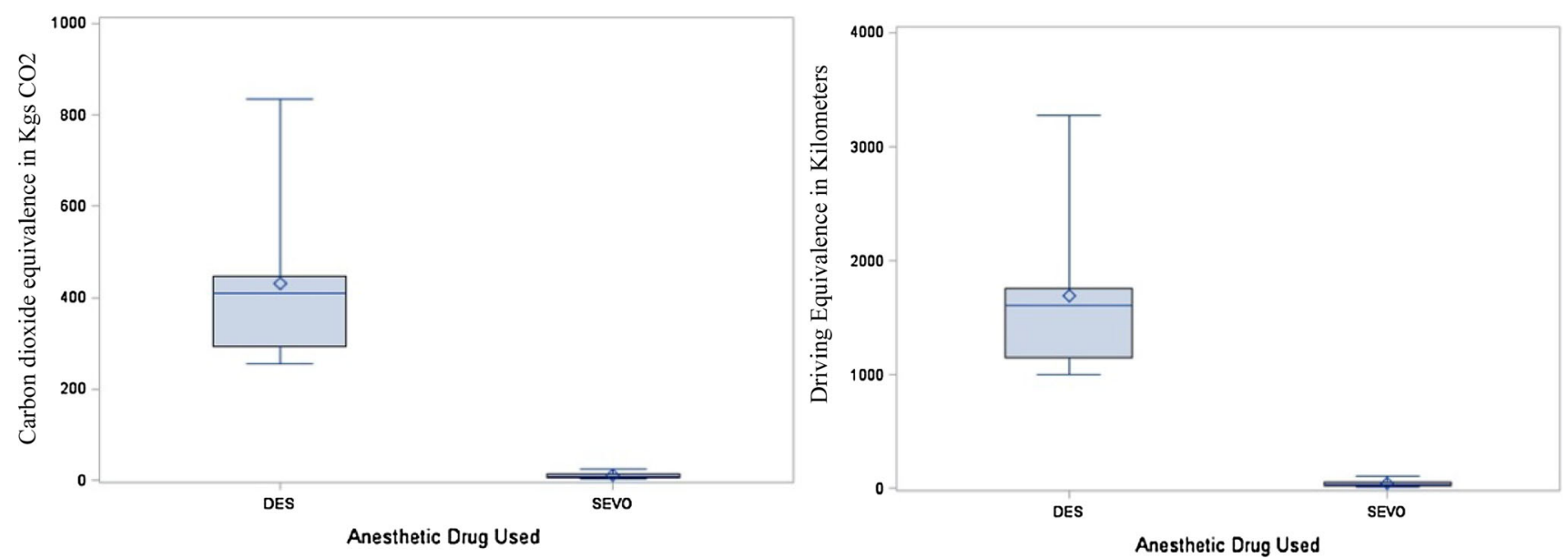

Figure Visual examination (median [interquartile range]) of the carbon dioxide equivalent and the kilometers driven equivalent of desflurane $v s$ sevoflurane during transanal total mesorectal excision procedures at Health Sciences North. DES = desflurane; SEVO = sevoflurane

scoring system $(P=0.89)$. There was no difference in the postoperative major morbidities rate nor mortality between the two agents.

The use of DES in the absence of a volatile scrubbing system (e.g., Deltasorb®; Blue-Zone Technologies Ltd, Concord,ON, Canada) is associated with a dramatic increase in CDE production. It is imperative to measure, monitor, and report CDE emissions of all medical treatments to direct efforts to reduce their carbon footprint. We showed that DES did not impact morbidity/mortality nor reduce PACU stay, but significantly increased the carbon footprint of the taTME procedure. We had previously reported the carbon footprint of DES exceeded SEVO by over 3 million KmDE based on sales data from 2016 at our hospital. ${ }^{5}$ The body of evidence on the carbon intensity of DES has now led to its removal from the formulary at our hospital in 2020 .

Acknowledgement Alison Vagnini (support with data collection).

Conflicts of interest None.

Funding statement None.
Editorial responsibility This submission was handled by Dr. Hilary P. Grocott, Editor-in-Chief, Canadian Journal of Anesthesia.

\section{References}

1. World Health Organization. COP24 Special Report Health \& Climate Change; 2018: 1-74. Available from URL: https://apps. who.int/iris/bitstream/handle/10665/276405/9789241514972-eng. pdf?ua $=1$ (accessed November 2019).

2. Özelsel TJ, Sondekoppam RV, Buro K. The future is now-it's time to rethink the application of the Global Warming Potential to anesthesia. Can J Anesth 2019; 66: 1291-5.

3. MacNeil AJ, Lillywhite R, Brown CJ. The impact of surgery on global climate: a carbon footprinting study of operating theatres in three health systems. Lancet Planet Health 2017; 1: e381-8.

4. Hanna M, Bryson GL. A long way to go: minimizing the carbon footprint from anesthetic gases. Can J Anesth 2019; 66: 838-9.

5. Mathur S, Ibrahim F. The contribution of the volatile anesthetics sevoflurane and desflurane on global warming at Health Sciences North, Sudbury, Canada. Anesthesiology Annual Meeting 2017: A488 (abstract). Available from URL: http://www.asaabstracts. com/strands/asaabstracts/abstract.htm?year=2017\&index= 15\&absnum=3502 (accessed November 2019).

Publisher's Note Springer Nature remains neutral with regard to jurisdictional claims in published maps and institutional affiliations. 